\title{
Exploring the Challenges and Potentialities of the Database of Religious History for Cognitive Historiography
}

Brenton Sullivan, Colgate University

Michael Muthukrishna, London School of Economics

Frederick S. Tappenden, McGill University

Edward Slingerland, University of British Columbia

\section{INTRODUCTION}

There are at least two ways in which cognitive historiography can be envisioned. The first, and by far the more common to date, centers on qualitative historical analysis that is either informed by knowledge about human cognition or driven by hypotheses drawn from some branch of the cognitive sciences. The second involves drawing upon quantitative analyses of historical data in order to test hypotheses about human cognition against the historical record. This latter approach is far more rare (exceptions include, e.g., (Clark and Winslett, 2011); (Slingerland and Chudek, 2011)). One of the main reasons for this is the dearth of quantitative historical data available to the scholarly community, as well as the difficulties of converting the thick, qualitative intuitions of historians into data structures. The Database of Religious History (DRH; http://religiondatabase.org) aims to respond to this gap. ${ }^{1}$ As an online, qualitative and quantitative encyclopaedia of religious cultural history, all entries to the DRH are provided by experts ranging all historical fields, with each entry being subject to peer-review by DRH regional editors. The chief focus of the DRH is primarily with regard to our knowledge of

\footnotetext{
${ }^{1}$ The Database of Religious History is hosted by the Cultural Evolution of Religion Research Consortium (CERC) at the University of British Columbia, Vancouver, Canada. It has been funded primarily, to date, by the Social Sciences and Humanities Research Council (SSHRC) of Canada, with additional funding or support from the John Templeton Foundation, UBC, the Peter Wall Institute for Advanced Studies, and the Center for Advanced Studies in the Behavioral Sciences (CASBS) at Stanford University.
} 
religious history, but eventually we plan to include many other aspects of the historical record (see further Slingerland and Sullivan (June 2017)).

Since its inception, the DRH has existed at the intersection of the sciences and the humanities. Aside from the immense challenges of designing a database robust enough to meet the needs of its array of users, and flexible enough to adapt to technological changes over time, the principal difficulties facing the DRH stem from the intersection of theory and practice. While the DRH was designed by a team of scholars and scientists, including biologists, psychologists, and ecologists, from the beginning the project has also been informed directly by historians of religion. Historians make up the vast majority of the project's personnel, ${ }^{2}$ and regular workshops with non-project-related historians have been hosted to gather their criticisms and suggestions. ${ }^{3}$ The reason for this is the belief that the cognitive-evolutionary theories and hypotheses that initially gave rise to the project must not dictate or contort the way that good history is done and, moreover, that these theories and hypotheses must somehow meet the historian where s/he stands.

In this paper we explore both the challenges and potentialities of the DRH project as a tool within the emerging field of cognitive historiography. We believe that databases like the DRH provide robust and essential tools for cognitive historiography, tools that open new methodological avenues for conducting historical research, and also enable the testing, refining,

\footnotetext{
${ }^{2}$ These include the director, Edward Slingerland, the current managing editor, M. Willis Monroe, and past managing editors Brenton Sullivan, Jessica McCutcheon, and Robban Toleno, the large (and growing) DRH Editorial Team, and of course the expert contributors themselves.

${ }^{3}$ These include the following workshops: "Prosociality in History and Historiography: Can Big Gods Tip the Balance in World History?" (University of British Columbia, October 17-19, 2014; sponsored by the Peter Wall Institute for Advanced Studies at the University of British Columbia); "Ritual and the Evolution of Religion and Morality" (University of British Columbia, November 26-27, 2014; co-organized by the Cultural Evolution of Religion Research and the Helsinki-based Ritual and the Emergence of Early Christian Religion research project); and "Religion, Ritual, Conflict, and Cooperation: Archaeological and Historical Approaches" (Center for Advanced Study in the Behavioral Sciences at Stanford University, April 29-30, 2016). In addition, the DRH benefitted from discussions with historians and others scholars of religion at the 2015 CERC Plenary Meeting (McGill University, May 8-10, 2015) and the "Methodological Innovation in the Study of Religions" panel at the XXI IAHR Congress (Erfurt University, August 23-29, 2015).
} 
and proposition of scholarly theories. Our focus is threefold. The first section of this paper draws attention to issues of methodology, specifically the technical challenges of constructing the DRH. In sections two and three we discuss the various units of analysis that populate the DRH; this includes units that already have clearly defined polls (section two), and those for which we currently are designing new polls (section three). By definition, such units must find utility across both scientific and humanistic inquiry, but they also must be consistent with the kind and nature of our historical sources. Finally, section four concludes with a broad discussion of the DRH's place within the field of cognitive historiography (specifically) and the broader field of Religious Studies (generally). ${ }^{4}$

\section{Building AND Designing the Database of Religious History}

The DRH is designed to become the largest online quantitative-qualitative encyclopedia of religious cultural history, as well as a central gateway to other online quantitative datasets and qualitative information about religion. From its inception, this has meant developing a data format appropriate for storing historical information and a software platform that made it easy to enter, browse, visualize, and analyze that information. The actual code and technical infrastructure were only a small part of the process. We faced three key challenges from the outset: (1) we did not know exactly what the system would look like or what features it needed to have; but (2) we knew that the database needed to be useful and usable for the variety of people involved (historians, anthropologists, economists, social psychologists, and the like); and (3) it

\footnotetext{
${ }^{4}$ Our focus in this article is quite programmatic; we seek to explore the design and overall utility of the DRH project. For a more concrete application of the DRH to a specific spatio-temporal location, see (Tappenden, 2017), which is a companion article to this one and is published in the same issue of the Journal of Cognitive Historiography. In that shorter piece, Tappenden focuses on a specific scholarly problem in the study of ancient Mediterranean religiosity, thus exploring the utility and potential of the DRH in historical scholarship.
} 
needed to be able to grow with our changing needs and changing technology — that is, it needed to be future-proof.

\section{UNCERTAIN REQUIREMENTS}

As is common in database and software development, we initially did not know what the final product would look like, nor what features it would need in order to be useful as a research tool. As software engineers are all too aware, the best solution is not always clear when one stands at the intersection of research problems and what is technically possible.

We dealt with this uncertainty using a software development paradigm known as Agile Software Development (Beck et al., 2001; Rubin, 2012). Under this model, at every stage of development one has a functional product that is iteratively improved by getting constant feedback from the various stakeholders. Because criticism is easier than composition, it is better to put something functional in front of people and have them tell you what is wrong with it rather than ask them what they want and trying to build a final product based on their descriptions. Accordingly, development of the DRH was not simply done in consultation with historians; it was driven by historians. In addition to the many workshops noted above (see n. 3), we also ran several usability studies with historians at UBC and collaborated with a User Experience

Designer and a User Interface Designer, both working in industry. Following the Agile approach, we iteratively improved the system by receiving feedback at every step of the way. A beneficial by-product of this approach is that, with every testing workshop, we have accumulated datasets that are now housed within the DRH.

From the start we knew that, if we wanted to be able to apply mathematical and statistical models to our data, we needed that data to be in a format amenable to such analyses. At the core of our data collection efforts is a spatio-temporal format, which we believe is ideal for historical 
data. All data we collect is captured and stored for a specific geographic region (Geographic Information System, or GIS) and time range (start and end year). Accordingly, for any particular variable or question, we are able to ascertain an answer (or degree of uncertainty), as it applies to a particular region of the world over a particular period of time. For example, we are able to say that apostates were punished in a particular region from 100-200 CE, but not in a neighbouring region and not from 200-400 CE. Although the DRH uses a novel spatio-temporal data format within the system, it is designed to enable data output in common formats, including shapefile (.shp) or Keyhole Markup Language (KML) for geographic data, and comma separated values (CSV) for all other data.

On top of this spatio-temporal format, we are able to attach a variety of data. Currently the system supports quantitative answers like "number of adherents to the religion," nominal answers such as whether supernatural monitoring was present or absent, and qualitative answers, mainly in the form of comments, but also through links to outside images or texts. ${ }^{5}$ Our system is designed with flexibility in mind, so we could in principle use our spatio-temporal format to capture images, ancient texts, or even 3D scans of artifacts. ${ }^{6}$ The key is—and this point is crucial — that all data in the DRH is not simply attached to a particular amorphous and hard to define group (such as Pauline Christianity, Shang Dynasty State religion, etc.), but instead attached to a particular geographic region and time range. We are, in effect, able to identify what practices and behaviours are happening in a certain geographic space in a specific temporal period.

\footnotetext{
${ }^{5} \mathrm{We}$ are also working on built-in tools that will allow experts to create their own custom databases of images or texts, linked to their entries, which among other things will allow them to publish research data they have gathered but that has remained locked up on their personal hard drive(s).

${ }^{6} \mathrm{We}$ are also in the early stages of collaborating with another team at UBC that is planning to spend the next 7 years gathering rich qualitative data on East Asian Buddhist sites (http://frogbear.org/).
} 


\section{USABILITY AND USEFULNESS FOR ALl STAKEHOLDERS}

The success of the DRH depends on its usefulness to all stakeholders. Analysts may be satisfied with CSV and KML files, but we also need to provide true value for the historians entering and using data in other ways. Indeed, historians are our most important stakeholders. ${ }^{7}$ The quality of our data is directly dependent upon the expert knowledge that historians bring, and the eventual utility of our datasets hold much promise for historical analyses. This means that the DRH must be easy for historians to use, and that the interface needs to hide the unnecessary technical complexity and allow experts to answer questions in something similar to a questionnaire.

When beginning an entry in the DRH, we ask experts to name the religious "group" they are entering data for, to specify a time range for that group, and to demarcate a regional map for that group using our GIS tool. Experts are instructed to pick the largest geographic region and time range for which most questions have homogenous answers. That is, we are looking for the largest area and time range for which it is reasonable to say, for example: "Yes, most of the people who I am identifying as part of group $\mathrm{X}$ and who lived in this place in this time believed in supernatural punishment." Because the historical and cultural record is never neatly circumscribed, the DRH allows experts to adjust either the region or time range for answers that vary over those defaults; that is, entries can easily be nuanced for instances when "they stopped believing after this time" or "this little city never had that belief." Moreover, answers are sourced and justified in comments, providing additional qualitative data. Our platform then seamlessly situates all answers in space and time.

Having our data in a spatio-temporal format allows historians to perform many analyses. For example, one could track cultural developments and show how they move through space and

\footnotetext{
${ }^{7}$ In addition to historians and interested researchers in anthropology, social-psychology, and the like, other stakeholders included educators, students, journalists, public policy makers, and members of the general public who wish to browse and visualize our data.
} 
time. This is not unlike how we track genetic mutations, and this kind of analytical potential allows historians to construct cultural phylogenies by which to see if packets of beliefs move in tandem, or to see if some beliefs predict the later emergence of others. ${ }^{8}$ With enough data, we could also reconstruct phylogenies, measure the similarity between two religious groups, or test evolutionary theories such as whether the presence of supernatural monitoring predicts largescale cooperation. Such potentialities naturally reverberate with cross-disciplinary resonances. As a tool for cognitive historiography, the DRH is at once grounded in the individual historian's expert knowledge while also presenting historians with a tool that allows for quantitative analyses of the historical record itself. In our view, such analyses are best integrated within and alongside the qualitative approaches that predominate much humanistic research, including cognitive historiography.

\section{FUtURe-Proof}

The final challenge was making sure we were thinking in years and decades: that is, that we were future-proofing our database. From a technical point of view, our platform was developed using the latest, but most robust open-source technologies. This allowed us to control the system from the ground up, and to ensure pliability for future upgrades. We chose to use the open-source Python Django framework as the backbone of our platform, to ensure maximum flexibility. Our database back-end is Postgresql and PostGIS; our front-end is written in HTML, CSS, and Javascript. Flexibility is achieved through the use of a Model-View-Controller design (Leff and Rayfield, 2001), which separates the front-end (view), from the back-end (model), from the logic connecting the two (controller). The front-end and back-end are effectively independent of each other, which enables us to make upgrades to either while retaining all data. Moreover, we use

\footnotetext{
${ }^{8}$ To date, studies of this kind have been localised to specific temporal and spatial locales (e.g., Matthews et al. (2013)). By contrast, the DRH will enable analyses at a more global level.
} 
Cloud Architecture to extend this abstraction to our hardware. By using a virtual cloud server, we can backup our entire system, clone it, or grow system requirements-increase RAM, bandwidth, or hard-drive space — at the click of a button.

The flexibility of the DRH extends beyond its technical design to comprise also the data points themselves. The DRH currently contains 230 priority variables and 220 non-priority variables, ${ }^{9}$ all of which have been devised by members of our research network over a three-year period. These variables are not hardcoded into the database. Instead, the questions and answer options are themselves data, abstracted from the platform so that they can be periodically revised and expanded. In this sense, our design is "data-agnostic." Any kind of data can be placed on top of our spatio-temporal format. Our current data consists of nominal, quantitative, and qualitative answers to questions, all of which exists in a "poll structure," which is essentially the relationship between questions (e.g., subquestions) and a convenient way to display the questionnaire to historians inputting data. In principle, however, any kind of data can be attached to the spatio-temporal backbone and displayed within the poll structure. This means that we have the ability to change and/or add to our questions and variables so as to adapt to the demands of differing fields of historical inquiry, or create entirely new polls of questions that go beyond our present research agenda. In this way, the DRH can meet the functional needs of historians across fields of study, and represents a general-purpose research tool usable by any research team to answer their own questions or pursue their own research agendas.

\section{THE "RELigious GROUP" IN THE DATABASE OF RELIGIOUS HISTORY}

As noted above, the DRH exists at the intersection of the sciences and the humanities. Actually implementing such a collaboration between these university sectors is, perhaps unsurprisingly,

\footnotetext{
${ }^{9}$ For a full list, see http://religiondatabase.org/about/questionnaire/.
} 
very difficult. We have continually struggled with connecting the often competing priorities and epistemes of these two camps. For example, since the inception of the DRH in 2012, something as basic as the unit of our analysis has proven difficult to define and demarcate. In this section we outline the progress of coming to an operational definition for our object of study, which we identify as the "religious group."

Despite the explanatory power of the theories and methods derived from the burgeoning field of cognitive science of religion (CSR), perhaps the greatest challenge facing its proponents is to find ways of applying CSR theories and methods to historical cases of religious phenomena. Our historical religious actors cannot be brought into a laboratory to be primed or studied using fMRI technology, nor can the ethnographer sit among them and engage in informal interviews or other methods conducive to writing an effective ethnography. All of our historical religious actors are dead, one result being that the dynamic exchange between participant and observer is lost. Moreover, the historian who dares to cross both time and space is much more at risk than his/her social scientist peer of foisting onto his/her subjects the frames of reference sensible to him/her but that would not necessarily be familiar to the historical religious actors in question.

This can be demonstrated by the analytical framework with which the DRH initially set out to study, which was focused less on historical religious actors and more on "Natural Geographic Regions" (NGRs). In collaboration with an early partner, the Seshat Global History Databank (Turchin et al. (2012); Turchin et al. (2015); https://evolutioninstitute.org/project/seshat/), we initially sought to divide the world's geography into a grid, with each square of the grid measuring approximately $10,000 \mathrm{~km}^{2}(100 \mathrm{~km} \times 100 \mathrm{~km})$. This sampling was conceived in order to document systematically areas that were relatively large enough to include influential cultural phenomena, but not so large as to conflate and/or overlook distinct 
cultural expressions. Time, likewise, was cut into 20-200 year increments-long enough to capture a group's cultural traits that prevail over historical happenstance, and short enough that changes due to cultural evolutionary forces could be detected using statistical regression models. With the unit of analysis established, the only task remaining was to define the attributes of the clusters of people thought to inhabit those times and places (that is, "space-times")

For example, one of the defined NGRs in China was the Middle Yellow River Valley (MYRV), the fertile area bounded by the Yellow River and the Wei River that gave rise to some of China's earliest and most prosperous dynasties. Adhering to the ideal parameters, a sampling region was drawn to include some of the principal urban centers located along the Wei River, such as Luoyang, Zhengzhou, and Kaifeng (see figure 1). ${ }^{10}$

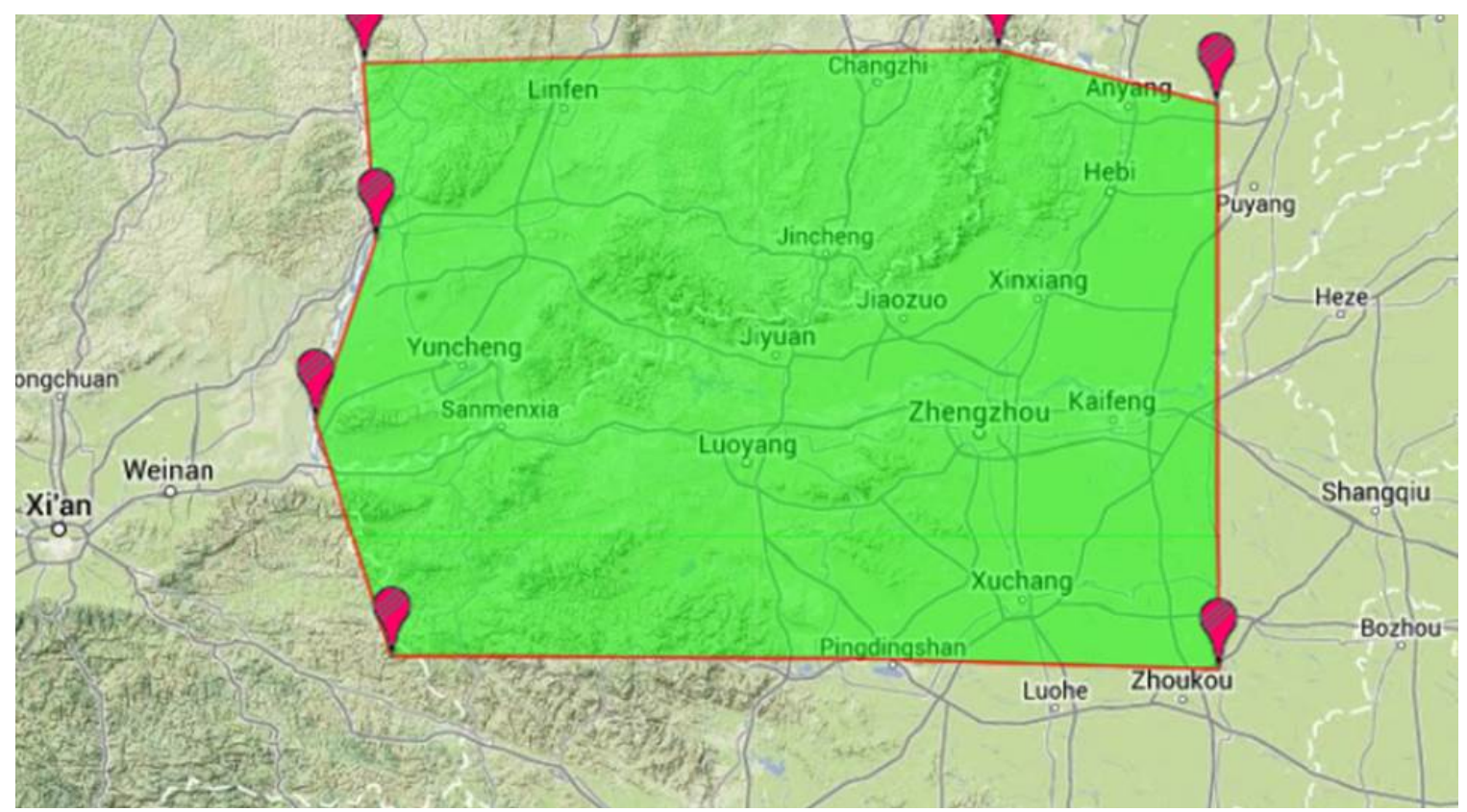

Figure 1.

Noticeably missing from this NGR is the important urban center of Xi'an, known as the Tang Dynasty capital of Chang'an. Moreover, the $10,000 \mathrm{~km}^{2}$ MYRV envisioned by economists and

\footnotetext{
${ }^{10}$ The polygon of the MYRV was drawn by Rudolf Cesaretti, research assistant for the Seshat project, and has as its base a Google map of the region.
} 
evolutionary theorists clashed with the much larger MYRV region typically envisioned by historians of China and other Sinologists (see figure 2). ${ }^{11}$

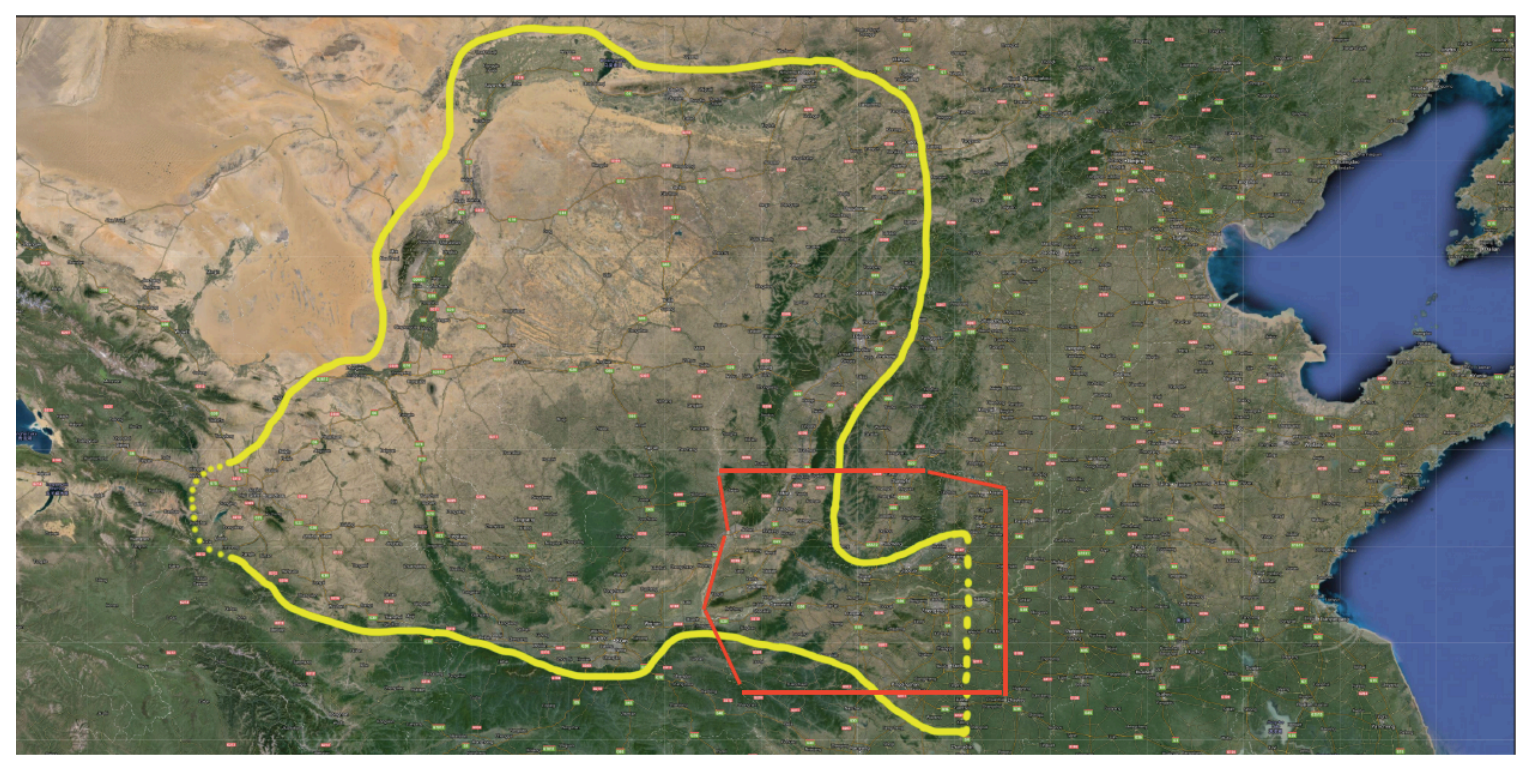

Figure 2.

While our envisioned strategy for sampling space-time units had a high level of precision with regard to the data collection, it essentially deprived the expert historians of the most important decision-making power-namely, their ability to define the object of study.

The original design of the database did not anticipate the challenges of working collaboratively with expert historians. The database's deceptively simple methodology required translation, or a filter, before the expert historian could be expected to contribute information. Ask any historian of religion to answer a set of "Yes/No" questions based on such ostensibly arbitrary parameters, and one will be met with confusion if not outright disgust. Moreover, historians of religion typically define themselves with reference to an area that is much larger than one of the predetermined NGRs, and when one asks an historian about his or her specialization, s/he often focuses on an area much smaller than this, because the good historian

${ }^{11}$ This rough but otherwise accurate outline of the MYRV was drawn by Dr. Robban Toleno, a former Managing Editor of the Database of Religion History, with a Google map as its base. The smaller, inset region is the same NGR found above in figure 1. 
follows the sources. That is to say, s/he starts with the sources that are usually identified with a very narrow location (if locatable at all), and then attempts to generalize and build a case for a larger area.

Although the overall project was designed with, and still maintains the goal of, collecting data pertaining to all manner of social and cultural history, we chose to focus the DRH first upon the collection of information relevant to religious phenomena. In so doing, the unit of analysis shifted from a prescribed NGR to the more general category of "religious tradition." The task of defining a geographic area and temporal range for the relevant "religious tradition" became a collaborative endeavor between DRH editors and the historian him/herself. However, DRH editors provided too little guidance in this process, and they also maintained an eagerness to cover large swaths of territory through individual entries. As a result, the entries that were set up were more similar to the familiar framework of a traditional encyclopaedia entry, and the geographic parameters for these entries sometimes exceeded the idealized $10,000 \mathrm{~km}^{2}$ (see figure 3).

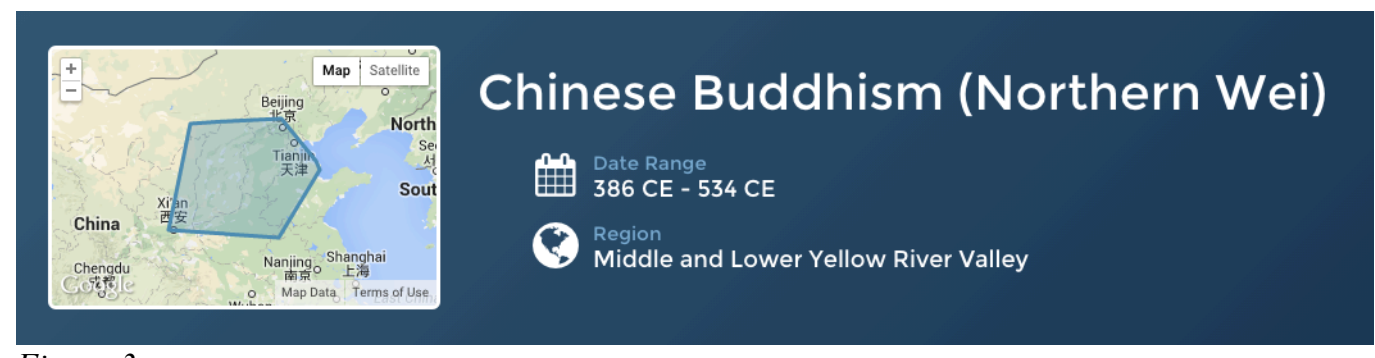

Figure 3.

Likewise, without well-defined editorial guidance, entries were created that far exceeded the ideal temporal sample of 20-200 years (see figure 4). 


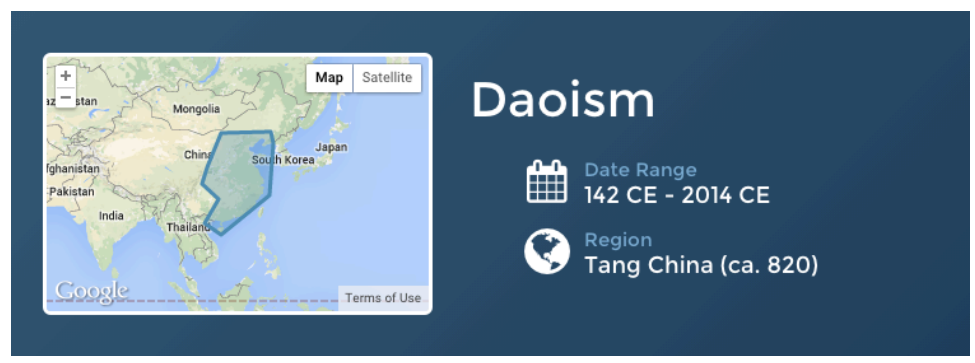

Figure 4.

The sought-after precision of space-time units was exchanged for the more familiar categories of religious history (e.g., dynastic periods, names of world religions). In sum, what this illustrates are the shortcomings of "religious tradition" as an analytical category, at least for the purposes of effective quantitative analysis. If the eminent historian Jonathan Z. Smith (1982: xiii) wants us to chart, connect, and analyze "specific acts of communication between specified individuals, at specific points in time and space, about specifiable subjects," then our project was veering away from the mark.

The concept of "tradition" encourages generalizations beyond the socio-historical context. "Traditions" are often conceived, even by veteran scholars, as beyond time. The whole point of a tradition is that it is constantly claiming and colonizing other spaces and times. "Tradition, like history, is something that is continually being recreated and remodeled in the present, even as it is represented as fixed and unchangeable" (Waterson, 1990: 232). "Tradition" also evokes the familiar categories of religious membership, such as "Christianity" and "Christians," "Buddhism" and "Buddhists." Membership in a religion is actually quite difficult to establish in many if not most pre-modern societies. It is more common that certain practices, beliefs, and/or institutions are held in common by people living in a common area (or across several, contiguous areas). So, membership and its related idea of patrolled boundaries of inclusion and exclusion should not be the defining criteria for our unit of analysis. Again, the thoughts of J. Z. Smith (1982: 18) on the study of religion are relevant here: 
What has animated these reflections and explorations is the conviction that students of religion need to abandon the notion of "essence," of a unique differentium for early Judaism as well as the socially impossible correlative of a community constituted by a systematic set of beliefs. The cartography appears far messier. We need to map the variety of Judaisms, each of which appears as a shifting cluster of characteristics which vary over time.

Smith's comment regarding the study of Judaism is equally applicable to the study of other "religious traditions," wherein our attention should be directed toward the components or traits of a group of historical religious actors, ${ }^{12}$ not in defining ahead of time a religious "tradition" or system in the abstract. Rather than foist upon the historical record (and the mind of the expert who is completing the questionnaire) a "tradition," it would be better to let the groups that share common beliefs, practices, and institutions emerge from the data itself. ${ }^{13}$

Still, some sort of "filter" or way of facilitating the expert historian's entry into the DRH was necessary. The solution upon which we landed was to employ the very social units studied by scholars themselves. A church, monastery, commune, intellectual community, sect, or other such group can be sufficiently discrete for deriving reliable and analyzable data. A "religious group" is locatable in space in time- the people who compose it are born and die in placeswhich is no doubt why it is the term used by so many other social science surveys and crosscultural studies (for a recent example, see Richerson et al. (2014)). The analytical term also has the advantage of being most familiar to the historian him/herself: rather than forcing the scholar to think about something as abstract as a "tradition" and to provide answers to a series of binary variables about such an amorphous entity, the scholar can determine him/herself the level of scale for the group.

In this approach, fidelity to the historical record (i.e., precision) and deference to the historian's judgment is paramount. DRH editors now encourage scholars to define the groups

\footnotetext{
12 This is not unlike what is advocated by Ann Taves' "building block approach" to the study of religion (see Taves (2009), (2011), (2015)).

13 This point emerged from discussions at the University of British Columbia between Brenton Sullivan and Joseph Henrich, now at Harvard University.
} 
for their entries as narrowly as is necessary to feel confident while answering questions about the presence or absence of certain traits associated with the group. We define the "religious group" as follows:

A community or network of people (locatable in space and time) who share common practices, beliefs, and/or institutions, but who are not necessarily conscious members of an explicitly recognized group. The group can be an emic (indigenous) name or category or an etic (scholarly attributed) one. ${ }^{14}$

Notably, the geographic parameters of a "group" are not determined by the project's preconceived NGRs. At the cost of not efficiently collecting data about a single region across time, contributing experts are assisted in providing a GIS polygon that more faithfully adheres to the know presence or influence of the historical actors in question. For instance, the entry titled "Northern Wei Buddho-Daoism" is geographically very narrow, consisting only of the immediate vicinity of the city of Xi'an (see figure 5).

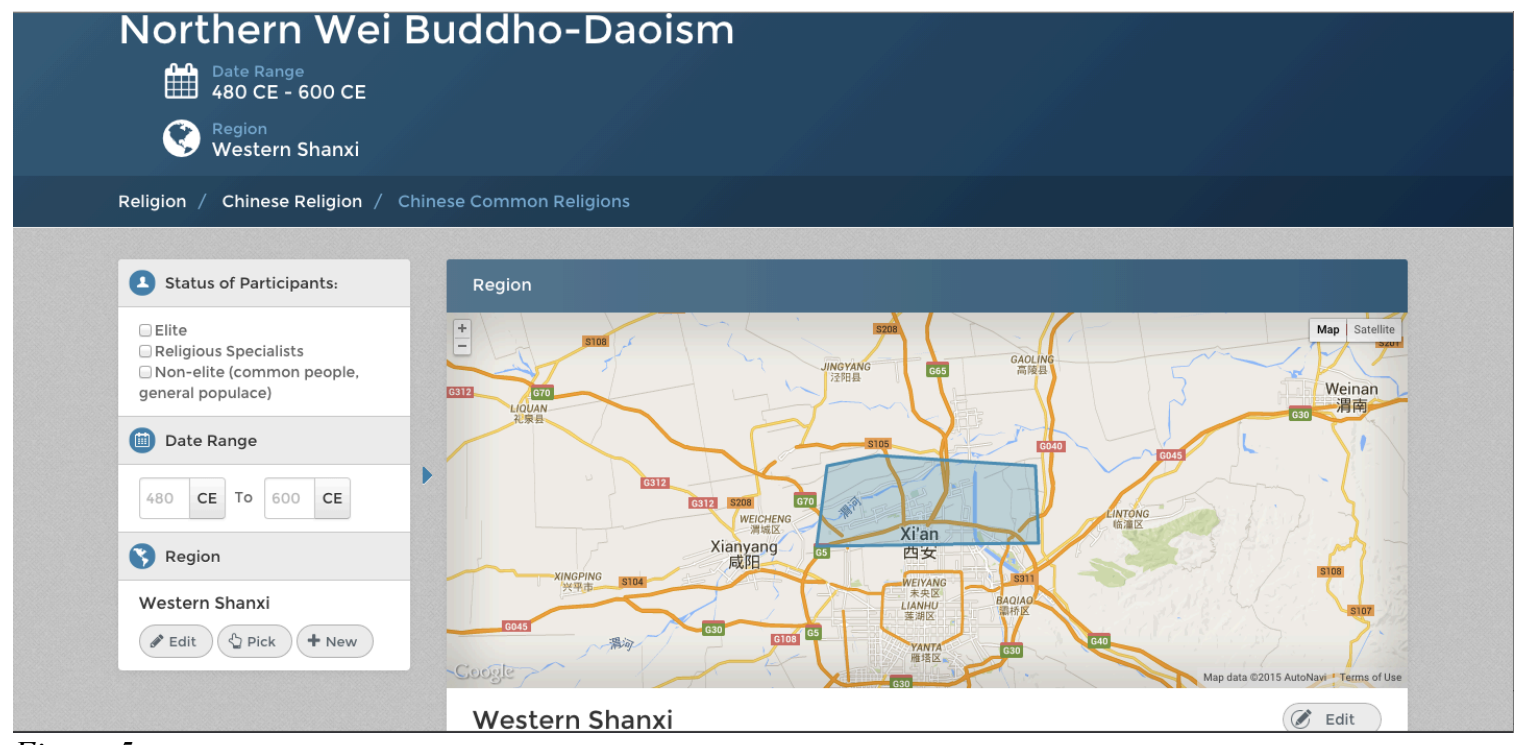

Figure 5.

In figure 5, note also that the temporal boundaries are more refined and, as a result, more tractable for both the expert historian entering the data and the analyst hoping to make use of the

\footnotetext{
${ }^{14}$ For more on the demarcation and definition of religious "groups," see (Tappenden, 2017).
} 
data for cross-cultural or diachronic analysis. The name of the entry, too, is more faithful to the diverse constellation of beliefs, practices, and institutions that existed among these historical actors. In short, scholars are now free to do something more akin to their usual, historical workfollow their sources and focus in on a discrete set of attestations about beliefs, practices, and institutions.

This approach better accords with our goal of collecting reliable data with which we can build a picture of religious change over space and time. In other words, rather than have our own preconceived notions of which "religious traditions" exist in the world and what characterizes their existence, the project designers and analysts have largely removed themselves from this stage of the process, allowing the historian to speak based on the historical record itself. Such an approach is compatible with attempts to derive polythetic definitions of religion, wherein the variety of features of a group are the focus, and wherein no single feature is either essential or sufficient for membership in a "religion" (see Saler, 1993). This allows for unexpected patterns of historical change or cultural exchange to emerge, such that chains of common attributes appear across times, places, and "religions." However, such patterns can emerge only when a suitable working relationship between theorists and historians is established and deference is given to the historian's trained impulses.

\section{FUTURE DiRECTIONS IN THE DRH}

By focusing on religious groups, especially when those groups are defined by the informed expert, we have been able to orient and galvanize our data collection efforts. Even still, this generally agreed upon unit of analysis has not always been well received by historians of religion. While many do study distinct social units (e.g., a church, monastery, commune, intellectual community, sect, etc.), others_- perhaps most—work primarily with texts and are 
trained to think and speak much more securely about interpretive themes and intellectual/cultural developments. The idea of abstracting cohesive social groups from texts alone, many of which may only be loosely connected to one another, does not always come easily. In our view, the main problem at work here is not an issue of right vs. wrong data collection efforts, but rather the recognition that the sheer variety and diversity of the historical record requires different kinds of data collection.

There is no such thing as a one-size-fits-all database poll. Instead, there is a pressing need to provide historians with an array of DRH polls that are properly suited to the different kinds of historical evidence with which they work. In response to conversations with historians and religious studies scholars, we are in the process of designing a series of new polls, to be organized around "Places" (temples, archaeological sites, cities, landscapes), "Texts," "Supernatural Beings," and "Rituals." In fact, DRH experts have already been using the "Religious Group" poll in this manner, defining their "groups" around these analytic units. ${ }^{15}$ Polls specifically designed around these other methods for slicing up the historical record, however, will do a better job of capturing relevant data and sit more easily with our expert respondents. Since all DRH data is ultimately grounded in space and time, these new poll answers will be fully integrated with our original "Religious Group" poll.

As a community resource, responsive to the needs of its users/contributors, the DRH has already been evolving into a platform quite different from that originally envisioned by its creators. Its use as a means for quickly and accurately assessing scholarly opinion in a field, in an age of information overload, has been foregrounded conceptually, and also practically

\footnotetext{
${ }^{15}$ See, for instance, Katrinka Reinhardt's entry on the archeological site Yanshi Shangcheng (http://religiondatabase.org/browse/entity/?entity=348\#/), M. Willis Monroe's entry on the "Scholars of Hellenistic Uruk" (http://religiondatabase.org/browse/entity/?entity=354\#/), or Caleb Simmons' entry on the Hindu ritual of Dasara (http://religiondatabase.org/browse/entity/?entity=390\#/).
} 
enhanced with new features such as an intuitive Affirm/Challenge/Comment function (Figure 6 below.)

\begin{tabular}{|c|c|c|}
\hline \multicolumn{3}{|c|}{ Answer History } \\
\hline \multicolumn{3}{|c|}{ < Go back to the entry } \\
\hline Show: & $\nabla$ Affirmations $\varnothing$ Challenges $\emptyset$ Comments & \\
\hline \multicolumn{3}{|c|}{ Is the cultural contact neutral: } \\
\hline \multicolumn{3}{|c|}{ Show older answers } \\
\hline \multicolumn{2}{|c|}{ Field doesn't know } & \multirow{2}{*}{$\begin{array}{l}\text { Benjamin Raffield The author } \\
\text { July } 24 \text { th } 2016\end{array}$} \\
\hline \multicolumn{2}{|c|}{ Status of Participants... Date range Region } & \\
\hline & Field doesn't know & \multirow[t]{2}{*}{$\begin{array}{l}7 \text { Claus Schmidt } \\
\text { August } 11 \text { th } 2016\end{array}$} \\
\hline & Status of Participants... Date range Region & \\
\hline & Field doesn't know & \multirow{3}{*}{$\begin{array}{l}\text { Amy Roberts } \\
\text { August 17th } 2016\end{array}$} \\
\hline & Comments / Sources: Field has no idea. This is an affirmation with a comment. & \\
\hline & Status of Participants... Date range Region & \\
\hline & Yes & \multirow{2}{*}{$\begin{array}{l}\text { Ivan Rouge } \\
\text { August 29th } 2016\end{array}$} \\
\hline & Status of Participants... Date range Region & \\
\hline & Yes & \multirow{3}{*}{$\begin{array}{l}\text { Andrew Richardsson } \\
\text { September 3rd } 2016\end{array}$} \\
\hline & $\begin{array}{l}\text { Comments / Sources: It is possible that certain groups might have accommodated the spread of } \\
\text { Christianity. For example, the Life of Anskar states that a Swedish king named Björn invited Anskar to } \\
\text { establish a mission at Birka. This is a challenge with a comment. }\end{array}$ & \\
\hline & Status of Participants... Date range Region & \\
\hline & Field doesn't know & \multirow{3}{*}{$\begin{array}{l}\text { Scott Kindergarden } \\
\text { September 12th } 2016\end{array}$} \\
\hline & $\begin{array}{l}\text { Comments / Sources: Well actually the field doesn't know only about the period till } 1050 \text { CE. Afterwards } \\
\text { the answer should be Yes. This is a challenge with different answer settings. }\end{array}$ & \\
\hline & Status of Participants... Date range Region & \\
\hline & Field doesn't know & \multirow{3}{*}{$\begin{array}{l}\text { Johanne Lee } \\
\text { October 30th } 2016\end{array}$} \\
\hline & $\begin{array}{l}\text { Comments / Sources: Well actually the field doesn't know only about non-elite and religious specialists, } \\
\text { whereas for the elite groups everything is clear. This is a challenge with different branching question } \\
\text { parameters. }\end{array}$ & \\
\hline & - Status of Participants... Date range Region & \\
\hline & Comment: I don't seem to understand the question. This is a standalone comment. & $\begin{array}{l}\text { Matt Brown } \\
\text { November 2nd } 2016\end{array}$ \\
\hline & Field doesn't know & \multirow{3}{*}{$\begin{array}{l}\text { Aleksey Ponomarev } \\
\text { December 12th } 2016\end{array}$} \\
\hline & Comments / Sources: This is the user's response (affirmation in this case). It can be edited. & \\
\hline & Status of Participants... Date range Region & \\
\hline & Comment: This is the user's comment. It can be edited. & \multirow[t]{2}{*}{$\begin{array}{l}\text { Aleksey Ponomarev } \\
\text { December 12th } 2016\end{array}$} \\
\hline & Edit & \\
\hline
\end{tabular}

AFFRM/CHALLNGE/COMMENT

Figure 6. A mock-up of the new Affirm/Challenge/Comment function and Answer History view (not real data) 
The DRH has also been responding to experts' desire for more focus on qualitative information. Various ways of using "skeletal" DRH entries - that is, entries with only part of the questionnaire filled out, but serving as a temporal-spatial anchor for attached data—are being explored. The desire for more contemporary ethnographic data has led to RA-based efforts to import data from the SCCS and eHRAF to the DRH. In an initiative led by William Scott Green, the University of Miami Department of Religious Studies plans to use the DRH in the classroom, having undergraduate students prepare DRH entries, under the supervision of a faculty supervisor, as a way of learning how to use textual and archaeological evidence, how to document opinions about the historical record, and other basic skills central to the humanities. We anticipate many new, unexpected uses for the DRH to develop as our user base increases.

\section{New Vistas on Cognitive Historiography}

In terms of the goals and methods specific to cognitive historiography, the purpose of the DRH is not to be yet another individual take on the "deep history" or cultural evolution of humanity, but rather to respond to the many calls that have been made for a historical dataset comparable to or even exceeding the ethnographic datasets already available (principally in the form of the Human Relations Area Files based at Yale; see Geertz (2014: 266)). Having such a tool readily available to historians opens new methodological possibilities and the ability to tackle new and old problems in historical studies. Grand explanatory schemas - especially ones that seem to suggest a directionality to history—have become anathema throughout the humanities. Partly this is a result of justifiable concerns about nineteenth and early twentieth century teleological accounts of world religious history by some of the pioneers of our field. The specter of "evolutionism" continues to haunt any large-scale, explanatory account of historical processes. We would argue, though, that our fear of evolutionism has caused us to throw out the 
explanatory baby with the colonialist bathwater. A recent, positive development in Religious Studies is a return to considerations of large-scale explanatory projects, combined with an openness to engagement with scholars outside of our field. In multiple venues, such as the American Academy of Religion and the International Association for the History of Religion, we are beginning to see genuine engagement between empirical researchers and historians, in a process that has the potential to enrich work on both sides of the humanities-science divide.

Cognitive Historiography also has a part to play in this, as it provides an interdisciplinary forum in which scholars can come together, test new methodological tools, and propose new theoretical paradigms. Generally speaking, we historians have yet to develop rigorous methods for substantiating generalizations about the historical record. Scholarly argumentation, in which we engage constantly, too often consists of exchanges of cherry-picked examples, with no real hope or expectation of being able to resolve differences of interpretation. This is an acute and novel problem for our generation of historians, and digital tools such as the DRH enable the kind of methodological advancement needed to push the discipline of cognitive historiography forward.

The DRH was originally conceived of as a way to evaluate rigorously large-scale explanatory theories of religion — such as those outlined in (Norenzayan et al., 2016a) and (Norenzayan et al., 2016b) — against the historical record, allowing quantitative approaches to cultural evolution while remaining firmly grounded in humanities expertise. In other words, it was designed to allow scholars to pose the sort of large-scale questions about the functionality of particular beliefs or practices in human cultural history that have hitherto been difficult to approach responsibly. As the project has developed, a whole suite of additional benefits has become apparent. For instance, the DRH allows historians who have no interest in large-scale 
theories to quickly and efficiently check their qualitative intuitions about the historical prevalence or distribution of beliefs and practices against those of their colleagues, and serves as a center for the documentation of scholarly disagreement. With powerful built-in visualization and analysis tools, the DRH also doubles as an engaging pedagogical tool. As noted above, we are hoping that other, as yet unforeseen, uses for the DRH will emerge as historians of religion explore its functionalities and suggest new features. What the DRH and other similar database projects ${ }^{16}$ have in common is a desire to harness the power and flexibility of the Internet and personal computers to provide cultural historians with a supplement to our traditional qualitative tools, allowing us to try to answer big questions more confidently, and in any case providing a quantitative check to our qualitative intuitions about any aspect of the historical record. Taken as a whole, the DRH promises to be an exceptional tool for cognitive historiography, one that pushes our methodological abilities beyond the standard qualitative approaches to now also bring quantitative assessments of the historical record into the mainstream of historical scholarship.

Perhaps the most exciting aspect of a project such as the one described here is the opportunities it provides for cross-disciplinary collaboration and the sharing of scholarly knowledge through an entirely new, open, and flexible web platform. We hope that, as the DRH grows over time, it will become a default reference source not only for scholars, but also teachers, students and the general public. As we have tried to illustrate in this paper, the creation of such new platforms is fraught with theoretical, practical, and social challenges-for one, inducing historians to contribute to an entirely new sort of scholarly reference work. The

\footnotetext{
${ }^{16}$ Other database projects are dedicated to exploring more narrow but potentially revealing aspects of the historical or archeological record, such as Roman trade routes as revealed in amphorae seals ((Remesal et al., 2014)), Carolingian coin hoards or shipwrecks in the Mediterranean (see list of databases at $\mathrm{http}$ //darmc.harvard.edu). One particularly important project for evaluating hypotheses about religion is the Pulotu Database of Pacific Religions (https://pulotu.econ.mpg.de/), which has already produced two important studies ((Watts et al., 2015); (Watts et al., 2016)). The DRH and Pulotu teams have recently entered into an agreement to incorporate some Pulotu data into the DRH.
} 
potential payoffs, however, are huge, including, for the first time, enabling the field of cognitive

historiography to tackle questions of historical cultural evolution with scholarly rigor and

scientific precision.

\section{Bibliography:}

Beck K, Beedle M, Van Bennekum A, et al. (2001) Manifesto for agile software development. Clark K and Winslett J. (2011) The Evolutionary Psychology of Chinese Religion: Pre-Qin High Gods as Punishers and Rewarders. Journal of the American Academy of Religion 79: 928933.

Geertz AW. (2014) Long-Lost Brothers: On the Co-Histories and Interactions Between the Comparative Science of Religion and the Anthropology of Religion. Numen 61: 255-280.

Leff A and Rayfield JT. (2001) Web-application development using the model/view/controller design pattern. Enterprise Distributed Object Computing Conference, 2001. EDOC'01. Proceedings. Fifth IEEE International. IEEE, 118-127.

Matthews LJ, Edmonds J, Wildman WJ, et al. (2013) Cultural Inheritance or Cultural Diffusion of Religious Violence? A Quantitative Case Study of the Radical Reformation. Religion, Brain and Behavior 3: 3-15.

Norenzayan A, Shariff A, Gervais W, et al. (2016a) The Cultural Evolution of Prosocial Religions. Behavioral \& Brain Sciences 39: 19 pages.

Norenzayan A, Shariff A, Willard A, et al. (2016b) Parochial Prosocial Religions: Historical and Contemporary Evidence for a Cultural Evolutionary Process. Behavioral \& Brain Sciences.

Remesal J, Díaz-Guilera A, Rondelli B, et al. (2014) The EPNet Project: Production and distribution of food during the Roman Empire: Economics and Political Dynamics. In: Orlandi S, Santucci R, Casarosa V, et al. (eds) Information Technologies for Epigraphy and Cultural Heritage: Proceedings of the First EAGLE International Conference. Rome: Sapienza Università Editrice, 455-464.

Richerson P, Baldini R, Bell A, et al. (2014) Cultural Group Selection Plays an Essential Role in Explaining Human Cooperation: A Sketch of the Evidence. Behavioral and Brain Sciences [Epub ahead of print]: 1-71.

Rubin KS. (2012) Essential Scrum: A practical guide to the most popular Agile process: AddisonWesley.

Saler B. (1993) Conceptualizing Religion: Immanent Anthropologists, Transcendent Natives, and Unbounded Categories, Leiden: Brill.

Slingerland E and Chudek M. (2011) The prevalence of mind-body dualism in early China. Cognitive Science 35: 997-1007.

Slingerland E and Sullivan B. (June 2017) Durkheim with Data: The Database of Religious History. Journal of the American Academy of Religion.

Smith JZ. (1982) Imagining Religion: From Babylon to Jonestown, Chicago: University of Chicago Press. 
Tappenden FS. (2017) The Database of Religious History and the Study of Ancient Mediterranean Religiosity. Journal of Cognitive Historiography.

Taves A. (2009) Religious Experience Reconsidered: A Building-Block Approach to the Study of Religion and Other Special Things, Princeton, NJ: Princeton University Press.

Taves A. (2011) 2010 Presidential Address: 'Religion' in the Humanities and the Humanities in the University. Journal of the American Academy of Religion 79: 287-314.

Taves A. (2015) Reverse Engineering Complex Cultural Concepts: Identifying Building Blocks of 'Religion'. Journal of Cognition and Culture 15: 191-216.

Turchin P, Brennan R, Currie TE, et al. (2015) Seshat: The Global History Databank. Cliodynamics 6: 77-107.

Turchin P, Whitehouse H, François P, et al. (2012) A Historical Database of Sociocultural Evolution. Cliodynamics 3: 271-293.

Waterson R. (1990) The Living House: An Anthropology of Architecture in South-East Asia, New York: Oxford University Press.

Watts J, Greenhill S, Atkinson Q, et al. (2015) Broad Supernatural Punishment but not Moralizing High Gods Precede the Evolution of Political Complexity in Austronesia. Proceedings of the Royal Society B-Biological Sciences 282.

Watts J, Sheehan O, Atkinson Q, et al. (2016) Ritual Human Sacrifice Promoted and Sustained the Evolution of Stratified Societies. Nature. 